\title{
ATENÇÃO NOS CUIDADOS DE ENFERMAGEM DAS ESCARAS QUANTO ÀS ASSOCIAÇÕES TERAPÊUTICAS
}

\author{
ATTENTION IN NURSING CARE FOR BEDSORES AS TO THERAPEUTIC ASSOCIATION
}

\section{Antonio de Magalhães Marinho ${ }^{1}$}

\begin{abstract}
RESUMO: O objetivo deste estudo foi levantar os tipos de prescrições e cuidados das escaras associados ao uso da pomada $I R U X O L^{\circledR}$, bem como os relatos das práticas de curativos usadas pela equipe de enfermagem nas unidades de internação. Foram analisados 19 prontuários de 3 hospitais de ensino do Município do Rio de Janeiro. Os resultados mostraram 8 diferentes tipos de prescrições médicas para o tratamento das escaras, sendo 4 associadas ao Iruxol ${ }^{\circledR}$. A formulação mais prescrita foi: limpeza com PVP-I + SF 0,9\% e IRUXOL®. Observou-se, ainda, que os profissionais de enfermagem aplicaram 17 combinações diferentes com diversas substâncias, sendo que 10 estavam associadas com o Iruxo ${ }^{\circledR}$. Relataram, também, o uso de 24 produtos / substâncias diferentes na realização dos curativos das escaras. Verificou-se, ainda, o uso indiscriminado de produtos que alteram o pH 1 teor ácido - base ) da lesão, fator este que interfere na ação desbridante do Iru$\left.\mathrm{xO}\right|^{\circledR}$.
\end{abstract}

UNITERMOS: Escaras - Cuidados - Tipos de tratamento.

\begin{abstract}
The present study aims at discussing the types of prescriptions and caring bedsores related to IRUXOL® ointment use, as well as bandages practice reports performed by the nursing team in care units. Nineteen patient files from three School Hospitals ins Rio de Janeiro city have been analyzed. The results presented eight different kinds of drug prescription for bedsore treatment in which four of them were related to $I R U X O L \circledast$. The most frequent formulation was: cleaning with PVP-I + Physiologic Solution $0,9 \%$ and IRUXOL ${ }^{\circledR}$. It has also been observed that the nursing professional had used seventeen different combinations with several substances in which ten of them were associated to IRUXOL®. They have also reported the use of 24 different products/substances when performing bedsores bandages. The indiscriminated use of products which alters injury pH (acid-base contents) such a factor which interferes debridant action of IRUXOL®, has been verified.
\end{abstract}

KEYWORDS: Bedsores - Caring - Types of treatment.

\section{INTRODUÇÃO}

Nos hospitais das grandes metrópoles há uma tendência crescente de aumentar o número de pacientes acamados, impossibilitados de por si sós se moverem no leito. Eles são classificados como de alto risco para desenvolverem complicações secundárias.

\footnotetext{
${ }^{1}$ Coordenador do Núcleo de Orientação de Pesquisas de Enfermagem do UCFF/UFRJ. - Chefe do Serviço de Desenvolvimento - DEN/HUCFF - Docente da Faculdade de Enfermagem - UERJ.
} 
As complicações mais comuns nesses pacientes são: 1. atrofia muscular provocando diminuição do tamanho da força do músculo; 2. contratura da articulação - provocando a limitação da amplitude dos movimentos; 3. distúrbios metabólicos, como: osteoporose, cálculos de trato urinário; 4. distúrbios esfincterianos ( incontinência urinária, fecal ou constipação); 5. deteriorização psicológica; 6. distúrbios circulatórios, como: hipotensão ortostática, pneumonia hipotática, trombose venosa e úlcéras de pressão ${ }^{11}$.

Dentre as complicações destacaremos as úlceras de pressão, que repre.sentam uma constante ameaça para os pacientes acamados e, principalmente, para aqueles que se encontram imobilizados no leito hospitalar.

As úlceras de pressão também são conhecidas como úlceras de decúbito ou escaras. As escaras são áreas de necrose localizadas na pele e tecido subcutâneo produzidas por compressão (Brunner \& Suddart ${ }^{4}$ ). Reforçando este conceito, Snowden ${ }^{18}$ afirma que "é qualquer lesão que tenha um rompimento da pele direta ou indiretamente associada com a pressão."

Autores como Campbell \& Delgado ${ }^{5}$ preocupam-se com os pontos do corpo de maior risco para o surgimento das escaras; descrevem que "são áreas de ulceração e necrose da pele que podem aparecer em qualquer parte do corpo, sendo mais freqüentes nas regiões com proeminências ósseas, submetidas a prolongadas e repetidas pressões".

Portanto, as proeminências ósseas que suportam o peso do corpo, recobertas apenas por pele e pequena quantidade de gordura subcutânea, são locais mais susceptiveis a abertura das escaras. Brunner \& Suddart ${ }^{4}$ destacam que $75 \%$ de todas as escaras se localizam no sacro, grande trocânter e tuberosidade isquiática. Outros pontos como maléolos e calcanhares, são também locais susceptiveis.

A escara ocorre quando a superfície corporal é comprimida pelas proeminências ósseas contra o colchão ou maca. O peso do corpo gera uma concentração da pressão nos pontos de contato e provoca isquemia e anóxia tecidual, e em conseqüência disso as células sofrem um processo de auto-agressão. A interrupção do metabolismo celular provoca a liberação de enzimas pela ruptura de organelas citoplasmáticas, instalando-se o processo de necrose celular. A superfície da pele com tecido neurótico rompe-se e forma uma úlcera. Então os microorganismos instalam-se provocando uma infeção no local. Em contato com os vasos linfáticos e sangüíneos, os microorganismos alcançam a corrente sangüinea provocando um quadro de sepsia. A infeção e a persistência da compressão provocam o comprometimento de estruturas corporais subjacentes, levando a situações irreversíveis e, muitas vezes, até a morte do paciente.

A escara constitui-se numa das mais sérias complicações no paciente acamado, a ser enfrentada pela equipe terapêutica.

Marinho ${ }^{11}$ concorda com Berecek ${ }^{2}$ e Bardsley et al $^{1}$ quando tratam do problema das úlceras de decúbito sob o aspecto econômico. Afirmam que o preço de uma escara é tríplo porque ela não só onera o paciente mas também a 
equipe terapêutica e toda a comunidàde. A formação de uma escara atrasa o programa de reabilitação do paciente, prolonga a separação de sua familia e ainda põe em risco sua vida com o surgimento de outras complicações. O entusiasmo da equipe terapêutica é afetado porque a presença de um paciente com escaras, freqüentemente, tem conotações de descuido e má assistência, provocando um sentimento de fracasso e culpabilidade. Por outro lado, a comunidade também é atingida porque a escara impede que o paciente retorne ao seu trabalho como um contribuinte potencial. Finalmente, o leito ocupado impede que outro paciente o use, aumentando assim a fila de espera dos indivíduos que necessitam hospitalização.

A incidência de escaras nos pacientes acamados é considerada como um fator negativo na avaliação da qualidade da assistência à clientela. Sendo o Enfermeiro o profissional incumbido do cuidado direto ao paciente, ele tem a responsabilidade de prever e prover os recursos necessários à prevenção e ao tratamento (cuidados) das escaras nas Instituições de Saúde e assim melhorar a sua imagem frente a comunidade.

Neste estudo abordaremos o uso do Iruxol $($ (colagenase + cloranfenicol) no cuidado / tratamento / recuperação das escaras em três Hospitais de Ensino do Município do Rio de Janeiro.

A escolha dos Hospitais de Ensino se deve ao fato de que é neles que se ensinam e disseminam os conhecimentos para os estudantes, futuros profissionais, responsáveis pelas práticas assistenciais empregadas nas demais Instituições de Saúde. Por outro lado, é neles que, também, se encontram, quase sempre, as condições favoráveis para a realização deste tipo de estudo.

A nossa preocupação se prende ao uso incorreto da pomada IRUXOL $®$ (colagenase + cloranfenicol) no cuidado/ tratamento/ recuperação das escaras, fato que prejudica a pronta recuperação da lesão e a ação efetiva da enzima colagenolítica nas feridas com tecido necrótico.

O uso de substâncias com fins terapêuticos devem seguir critérios rigorosos para se obter os resultados desejados o mais rápido possível. Com a observação desses critérios, obtém-se a recuperação do paciente, pela ação eficaz do medicamento, bem como o reconhecimento terapêutico para o qual está sendo indicado.

\section{OBJETIVOS DO ESTUDO}

Este estudo tem por objetivos:

- Levantar os tipos de tratamentos de escaras com o emprego do Iruxol $($, prescritos pelos médicos nas unidades assistenciais dos hospitais de ensino da cidade do Rio de Janeiro.

- Analisar as prescrições médicas de Iruxo|® com as práticas e técnicas aplicadas pelos profissionais de enfermagem no cuidado das escaras.

- Destacar as medidas que favoreçam o uso adequado da pomada Iruxol® na terapêutica das escaras. 


\section{REVISÃO DA LITERATURA}

\section{Bases Teóricas Sobre a Pele e a Cicatrização}

A pele é uma estrutura de extrema importância para o corpo humano. Além de proteger, èla ajuda a manter a sua temperatura, capta uma série de informações para o sistema nervoso e contribui para a eliminação de resíduos orgâni$\cos ^{11}$.

A pele é formada por três camadas: a epiderme, que é a mais superficial; a derme, que é a intermediária; e a hipoderme ou tecido subcutâneo ou tecido celular intermediário, que é a mais profunda delas.

A epiderme é composta por várias camadas: a córnea, que é a mais superficial e acumula uma substância chamada queratina, produzida nas camadas subjacentes. A camada germinativa ou basal é a mais profunda, e a responsável pela renovação da epiderme, sendo delimitada pela membrana basal, que separa a derme.

$\mathrm{Na}$ epiderme encontramos também células especiais chamadas melanócitos. Estas participam da produção e armazenamento da melanina, o agente de pigmentação da pele.

A derme apresenta um tipo de tecido conjuntivo de sustentação, onde estão localizados os vasos que formam a microcirculação. Nesta camada também estão as estruturas linfáticas, nervosas, glândulas e folículos pilosos, além de elementos celulares produtores de diversos tipos de fibras.

É através dos fibroblastos, células do tecido conjuntivo, que a pele se renova. Quando a pele é agredida ocorre uma lesão. As lesões são classificadas de acordo com o grau de prejuízo aos tecidos: - lesões sem perda da pele, como os cortes por material pérfuro-cortante; - lesões com perda da epiderme, como nas escoriações; - lesões com perda da epiderme e da derme, como é o caso das queimaduras, das úlceras varicosas e das escaras.

O ser humano esta sujeito a lesões de diversas origens, que podem ou não estar acompanhadas de infeção.

Sempre que é agredido o organismo desencadeia uma reação, denominada de processo inflamatório. Quando o processo está em declínio o organismo inicia o processo de cicatrização.

Martins et al ${ }^{12}$ ressaltam que o processo de cicatrização "é caracterizado por uma mudança contínua levada a cabo por um grupo de células, cada qual com um papel especifico". Este processo comporta três fases que se sobrepõem: inflamatória (fase 1), reconstrução (fase 2) e maturação (fase 3). A primeira fase funciona como uma resposta do tecido à irritação. A reação inicial é a vasoconstrição; com isso a circulação torna-se mais lenta porque os leucócitos concentram-se cada vez mais na parede dos vasos dilatados. Os capilares próximos da ferida tornam-se mais permeáveis e o exsudato inflamatório infiltra-se na ferida. Há nessa fase um aumento de sinais de inflamação (tumor, rubor, ca- 
lor e dor). A fase 2 (reconstrução) é caracterizada pela remoção de tecido morto e bactérias, para dar lugar 'a cicatrização (reparação). Nesta etapa há uma aceleração na produção de tecido neoformado rico em colágeno. Os macrófagos em maior número assumem a operação; os neutrófilos diminuem; há um aumento de monócitos fagocíticos e o aparecimento de grande quantidade de fibroblastos. É na última fase (maturação) que a estruturação do novo tecido da cicatrização é remodelado. Nesta fase o colágeno originalmente distribuído ao acaso, vai ser destruído e substituído por novas fibras colocadas de forma anatômica, isto é, ao longo da linha de tensão. Existe uma série de fatores que influenciam na cicatrização das feridas. Elas podem ser locais ou sistêmicas; dentre elas destacam-se: os inerentes aos pacientes, como: idade, sexo, tipo de doença (aguda ou crônica), estado nutricional, resistência orgânica, tipo de lesão e tecido lesado; os relacionados aos procedimentos, como: técnica de curativo, presença de corpos estranhos, (substâncias, bactérias ou resíduos orgânicos ou inorgânicos), hematomas, infeção e pensos (material de curativos). Os outros fatores que retardam a cicatrização são: anomalias congênitas, anemia, déficit de oxigênio, temperaturas extremas, icterícia, uso de medicamentos imunossupressores, esteróides e citotóxicos. A presença de doenças crônicas como diabetes, doenças oncológicas, insuficiência renal e vascular, bem como o estado de desnutrição, reduzem a capacidade de síntese do colágeno. As deficiências vitamínicas, a má nutrição e a obesidade influem negativamente no processo de cicatrização.

\section{Bases Teóricas Sobre Úlceras De Pressão}

A pressão é mencionada como a causa primária das escaras. A intensidade e a duração são importantes porque, enquanto a pele resiste a altas pressões por curto espaço de tempo, sem lesões, ela freqüentemente se lesa como resultado de baixa e moderada pressão, quando mantidas por um periodo de tempo prolongado.

Lowthian ${ }^{10}$ afirma que uma pressão de $100 \mathrm{mmHg}$ é suficiente para produzir escaras profundas em animais sadios. Pfaudler ${ }^{16}$ mostrou que 0 máximo de pressão normalmente encontrado, no homem na posição deitado, é entre 50 $100 \mathrm{mmHg}$. Para o indivíduo sentado, o nivel de pressão é em torno de 80-200 $\mathrm{mmHg}$. Brunner \& Suddarth ${ }^{4}$ afirmam que $32 \mathrm{mmHg}$ é suficiente para ocluir capilares na pele e levar à formação de escaras.

Berecek ${ }^{2}$ cita estudos de Groth, que identificou dois grupos de escaras: as de forma superficial, benigna, e as de forma profunda, maligna. As primeiras começam na superfície da pele e evoluem até atingir as camadas mais profundas. As segundas iniciam nos planos mais profundos e aflora à superfície.

Rubin et $a^{17}$ classificam as fases de uma escara em três estágios bem definidos: - A fase I compreende distúrbios circulatórios transitórios e mostra um hiperemia reativa na área da pele submetida a pressão. A fase II é caracteriza- 
da por comprometimento da circulação superficial, havendo formação de hiperemia permanente, que não desaparece com o alívio da pressão. Esta, posteriormente, evolui com arroxeamento e edema (tumefação) local. A seguir verificase a formação de flictena (vesículas serosas) que se rompem, produzindo escoriações e posteriormente necrose epidérmica com ulceração superficial. A fase III mostra necrose profunda com comprometimento do tecido adiposo subcutâneo, das fácias musculares, músculos e até dos ossos subjacentes.

Snowden ${ }^{18}$ focaliza a infecção secundária por stafilococus como a complicação mais comum no processo de formação de escaras profundas.

Em relação a susceptibilidade para contrair escaras Mulholand et al ${ }^{15}$ analisaram o balanço nitrogenado em um grupo de 35 pacientes com escaras, observaram que os niveis de proteína plasmática nesses pacientes era sempre negativa. A cicatrização das lesões só começava quando o nível passava para positivo, com a administração de dieta rica em aminoácidos e dextrose.

Ainda em relação a dieta Mccormick $^{13}$ recomenda o uso de vitaminas como complemento alimentar, para melhorar o quadro do paciente e auxiliar no processo de cicatrização.

Brunner \& Suddarth ${ }^{4}$ destacam a administração de derivados de ferro e vitamina $C$.

As causas das escaras, bem como os fatores que influenciam no processo de recuperação/cicatrização foram agrupados por Woodbine ${ }^{20}$ nas seguintes categorias: - pressão causada por força direta; 2 - pressão causada por força paralela/acizalhamento; 3 - fatores externos, como umidade (urina, exsudato, suor, etc.), substâncias irritantes, bactérias e calor; 4 - fatores internos, como pirexia, anemia, desidratação, uremia, desnutrição e deficiências de vitaminas C e deficiências vasculares. O processo de recuperação da escara sofre influências de várias ordens: doenças degenerativas, diabetes, hipertensão e outras patologias, contribuem de forma negativa para a cicatrização. Portanto, a evolução da escara sofre influências do estado geral do paciente. Os pacientes em bom estado nutricional e geral podem evoluir para a formação de ulcerações rasas, que se mantém por longos periodos sem progressão para as demais fases, mesmo quando já atingiram a fase II, podem evoluir para a volta gradual ao normal. No paciente debilitado, a evolução pelas fases e mais rápida, com ulceração mais extensas e profundas. Quase sempre estas são complicadas mais ainda por infeção que pode chegar a septicemia e se constituir em uma das principais causas de morte (Boghossian ${ }^{3}$ ).

\section{Aspectos Teóricos sobre a Colagenase ( Iruxo/ ${ }^{\circledR}$ )}

No Dicionário de Especialidades Farmacêuticas (DEF) ${ }^{8}$ esta registrado que o Iruxol $^{\circledR}$ é a preparação enzimática do Clostridium histolyticum, que contém como principal componente a COLAGENASE (clostidiopeptidase A), além de outras peptidases com o antibiótico Cloranfenicol, homogeneizado em pomada lipofilica anidra. 
A composição de 1grama $(\mathrm{g})$ de pomada lipofilica anidra contém 0,6 UI de colagenase e $0,01 \mathrm{~g}$ de cloranfenicol. Suas indicações são para desbridamento de crostas e necroses, independente de causa e localização: úlceras de perna (varicosas) úlceras de decúbito, gangrena de extremidades (diabética e de congelamento), lesões pós-operatórias, por irradiação ou áreas receptoras de enxertos. Com a terapêutica com Iruxol ${ }^{\circledR}$ observa-se atividade enzimática após um e no máximo 14 dias em $97 \%$ dos pacientes. A colagenase libera as partes de tecido/ fibras de colágeno em seu estado natural que mantém o tecido necrótico preso vivo no fundo da ferida, o que impede a formação do tecido de granulação. Portanto, além do caráter enzimático/desbridante a colagenase indiretamente estimula a formação do tecido de granulação e posteriormente a reepitelização. Ela age com pH entre 6,8 e 7,5, sendo inativada com pH inferior a 5,5 e superior a 8,0. É também inativada pela ação de detergentes, benzalcônio, iodo e metais pesados (mercúrio, prata e sais de zinco). Os antibióticos não modificam sua eficácia. ${ }^{8,9,14}$

No Iruxol ${ }^{\oplus e ́ ~ o ~ C l o r a n f e n i c o l ~ o ~ a n t i m i c r o b i a n o ~ q u e ~ e s t a ́ ~ a s s o c i a d o ~ a ~ c o l a g e n a-~}$ se. $O$ cloranfenicol foi o primeiro antibiótico de amplo espectro produzido em laboratório. Foi isolado do streptomyces venezuelae. $\mathrm{Na}$ atualidade e sintetizado. O principal derivado e o tianfenicol. Ele é primeiramente bacteriostático, embora possa ser bactericida contra certas espécies, em determinadas condições. Inibe a síntese protéica das bactérias. $O$ cloranfenicol mostra-se eficaz contra microorganismos gram-positivos e negativos, Rickettsia, clamydia e mycoplasma. Constitui o antibiótico mais eficaz no tratamento de infecções por salmonella e por bacterióides, bem como infecções por anaeróbios. Durante o uso podem aparecer reações de hipersensibilidade, inclusive com o uso tópico. As doses terapêuticas do cloranfenicol podem interferir na resposta anamnésica ao toxóide tetânico de modo que nâo pode ser utilizado com a imunização ativa. Inibe a biotransformação das drogas metabolizadas pelas enzimas microssômicas hepáticas. Pode causar depressão medular levando a anemia, reticulocitopênica e leucopenia $\left(\mathrm{DEF}^{8}\right)$.

\section{A Cicatrização das Úlceras de Pressão}

O processo de cicatrização das úlceras de pressão em pacientes acamados sem levar em consideração o tamanho e profundidade da mesma, a pressão sobre a área deve ser eliminada. A úlcera não irá cicatrizar até que toda pressão seja removida. O paciente não deve ser posicionado sobre a úlcera, mesmo por alguns minutos. A prescrição individualizada com um plano de mudanças sistemáticas de posição devem ser seguidos cuidadosamente pela equipe de enfermagem ${ }^{11}$.

Logo após uma lesão o sangue e o exsudato, formado pelos elementos liberados pelos vasos sangüíneos, desidratam-se e se solidificam, formando uma crosta.

A crosta protege a granulação tissular contra invasão de microorganismos e traumas. $O$ tecido de granulação é formado por capilares recém-formados e por fibroblastos. 
$\mathrm{Na}$ derme as células do sistema retículo epitelial multiplicam-se lentamente em direção ao centro da lesão, acompanhados por brotos marginais. A lesão estreita-se e apresenta-se mais ou menos limpa e contém apenas fibrina que vai sendo destruida pelos fibroblastos à medida que avança sobre ela.

O tecido epitelial, localizado nas bordas da lesão, inicia uma intensa reprodução migrando para o centro da lesão por cima do tecido conjuntivo de granulação. Simultaneamente na derme, elementos celulares produzem fibras de tecido conjuntivo, principalmente o colágeno. Esta fase é conhecida como fase colagenolítica.

Tanto as crostas quanto o tecido necrótico estão fixos no fundo da lesão por meio de pontes de colágeno. Estas pontes permanecem ancoradas no fundo da lesão retardando a migração dos elementos figurados.

As crostas são constituídas por cerca de $80 \%$ de fibrina. Nas necroses e nas escaras, que são massas de tecido desvitalizado (necrosado) há cerca de $80 \%$ de colágeno desnaturado, e a colagenase, uma enzima produzida pelos fibroblastos, que destrói o colágeno e impede o crescimento excessivo do tecido de granulação. Com isso há um equilibrio entre a produção e a remoção do colágeno ${ }^{10}$.

Além disso, o estado nutricional inadequado e as anormalidades hidroeletrolíticas devem ser corrigidas para promover a cicatrização. Ferimentos que drenam líquidos corporais e proteínas colocam o paciente em estado catabólico e o predispõe a hipoproteinemia e infecção secundárias graves. A deficiência de proteínas deve ser corrigida para cicatrizar a úlcera de pressão. Os carboidratos são necessários para "poupar" a proteína e proporcionar uma fonte de energia. A vitamina $\mathrm{C}$ e os oligoelementos, especialmente o zinco, são necessários para a formação do colágeno e cicatrização do ferimento ${ }^{4}$.

Para permitir a cicatrização das úlceras de pressão no estágio I a pressão é removida para favorecer o aumento da perfusão tissular, melhora do estado nutricional e hidroeletolítico, redução das forças de fricção.

As úlceras de pressão no estágio II apresentam rompimento da pele. Além das medidas listadas para as úlceras de pressão no estágio I, um ambiente úmido é desejado para auxiliar a cicatrização do ferimento. A migração das células epidérmicas sobre a superfície das úceras ocorre mais rapidamente em um ambiente úmido. Um curativo oclusivo semipermeável ou curativos salinos úmidos são úteis para proporcionar um ambiente úmido, para cicatrizar e reduzir ao mínimo a perda de líquidos e proteínas a partir do corpo. ${ }^{19}$

As úlceras de pressão nos estágios III e IV apresentam lesão tissular extensa. Além das medidas listadas para o estágio I, essas úlceras de pressão necróticas, avançadas e drenando, devem ser limpas (desbridadas) para criar uma área que irá cicatrizar. O tecido necrótico (desvitalizado) favorece o crescimento bacteriano, retarda a granulação e inibe a cicatrização. A limpeza dos ferimentos e os curativos são desconfortáveis. Portanto, o enfermeiro deve preparar o paciente, explicar o procedimento e administrar analgesia prescrita quando necessário ${ }^{17,3}$. 
O desbridamento pode ser realizado por modificações de curativos molhados e úmidos, lavagens mecânicas do exsudato nécrótico e infectado, aplicações de preparações enzimáticas prescritas que dissolvem o tecido necrótico, ou dissecção cirúrgica. Se uma escara cobre a úlcera, ela é removida cirurgicamente para assegurar uma ferida limpa e vitalizada. O exsudato pode ser absorvido por curativos ou pós, espumas ou géis hidrofílicos especiais. As culturas das úlceras de pressão infectadas são obtidas para orientar a seleção da antibioticoterapia $^{3,11}$.

Depois que a úlcera de pressão for limpa, um tratamento tópico é prescrito. A meta da terapia é promover a granulação. O novo tecido de granulação deve ser protegido da reinfecção, ressecamento, e lesão ao tecido em fase de granulação. Cuidado deve ser tomado para impedir um traumatismo adicional à área.

Curativos, soluções e ungüentos aplicados a úlcera não devem romper o processo de cicatrização. Agentes e protocolos múltiplos são utilizados para tratar as úlceras de pressão. A persistência é uma chave importante para o sucesso. Alem disso, uma avaliação objetiva, da resposta da úlcera de pressão , ao protocolo de tratamento deve ser feito a cada 4 a 6 dias. Pode levar um tempo longo para ocorrer a cicatrização de uma úlcera de pressão. A intervenção cirúrgica é necessária quando a escara é extensa, quando existem complicações potenciais (com fístula), e quando a úlcera não responde ao tratamento. Os procedimentos cirúrgicos incluem a incisão e drenagem, enxerto de pele, ressecção óssea, bordas de pele e bordas miocutâneas ${ }^{3}$.

\section{MATERIAL E MÉTODOS}

Este estudo de caráter exploratório, foi desenvolvido em três hospitais de ensino do Município do Rio de Janeiro, no período de março a maio de 1996. A população foi constituida por todos os pacientes com escaras de pressão. A amostra constou de 19 pacientes portadores de patologias clínicas e cirúrgicas, que os mantinham restritos ao leito hospitalar. A técnica de coleta de dados consistiu da busca ativa nos prontuários desses pacientes (evoluções e prescrições médicas e de enfermagem), bem como, da análise das informações dos profissionais de enfermagem responsáveis pela troca dos curativos.

\section{RESULTADOS}

Dos 19 prontuários examinados 07 foram da instituição A e 06 de cada uma das instituições $\mathrm{B}$ e $\mathrm{C}$. Em relação à clínica em que ficaram internados, predominantemente, foram $1.1 \mathrm{da}$ Cirurgia e 08 da Clínica Médica. Quanto ao sexo: 12 eram do feminino e 07 do masculino. A idade dos pacientes variou entre 33 e 73 anos, com mediana de 59 e média de 57,6 anos. 
Nos hospitais A e B os profissionais responsáveis pela troca dos curativos das feridas crônicas, tipo úlceras de perna e escaras, é indiscriminadamente o Enfermeiro ou o Auxiliar/Técnico de Enfermagem; no hospital C a responsabilidade é do Enfermeiro.

No Quadro Demonstrativo I verifica-se que os 19 pacientes apresentam um total de 28 úlceras de pressão. As regiões de maior incidência foram a sacra e coccígea com $13(46,4 \%)$ das lesões, seguida da região do calcâneo com 4 $(14,2 \%)$. Em relação ao número de dias necessários para instalação da lesão variou entre 9 e 27 dias após a internação, com média de 16,6 dias e mediana de 16,5 dias. Observa-se também que $9(47,3 \%)$ dos pacientes desenvolveram duas escaras. Das 28 lesões, $17(60,7 \%)$ chegaram a fase II, com comprometimento da pele (epiderme e derme) e do tecido celular subcutâneo, $8(42,1 \%)$ chegaram a fase III, com comprometimento da pele, tecido subcutâneo (adiposo) e musculatura, e 3 chegaram a fase IV, a mais grave, pois compromete além do músculo chegando as estruturas ósseas.

Das escaras analisadas $100 \%$ apresentaram estágios de infeção, sendo que somente em $9(32,1 \%)$ foram realizadas culturas para antibiograma. Apurou-se que foram realizados desbridamentos mecânico/cirúrgicos em $12(42,8 \%)$ escaras que continham tecido necrosado. Nos prontuários destes pacientes, nem sempre foi prescrita pelo médico ou observada pelo profissional de enfermagem uma prévia cobertura profilática com antibióticos para prevenir um quadro séptico, uma vez que após o desbridamento da crosta o tecido de granulação fica exposto podendo ocorrer disseminação bacteriana pelos vasos linfático e corrente sangüinea.

Verifica-se ainda no Quadro I que foram aplicadas 2 e até 5 formulações terapêuticas para tratamento da mesma lesão. $O$ período médio de recuperação/ cicatrização das escaras, no grupo / amostra estava acima de 40 dias. 


\section{QUADRO DEMONSTRATIVO I - CARACTERÍSTICAS DOS PACIENTES PORTADO- RES DE ESCARAS TRATADOS/CUIDADOS COM IRUXOI ${ }^{\circledR}$ NAS INSTITUIÇÕES ESTUDADAS}

\begin{tabular}{|c|c|c|c|c|c|c|c|c|c|c|c|}
\hline $\mathrm{N}^{0}$ & Sexo & Idade & Diagnóstico & Local da Escara & $\begin{array}{l}\text { Apare- } \\
\text { cimento da } \\
\text { Escara } \\
\text { (dias) }\end{array}$ & $\begin{array}{l}\text { Classificação } \\
\text { (Fases das } \\
\text { Escaras) }\end{array}$ & $\begin{array}{l}\text { Infeção s/n } \\
\text { SWAB * }\end{array}$ & $\begin{array}{l}\text { Desbri- } \\
\text { damento } \\
\text { Cir. s/n }\end{array}$ & $\begin{array}{l}\text { Tipos de } \\
\text { Curativos } \\
\text { (Quadro II) }\end{array}$ & $\begin{array}{l}\text { Cicatri- } \\
\text { zação } \\
\text { (dias) }\end{array}$ & $\begin{array}{l}\text { Quantidade } \\
\text { de prescri- } \\
\text { ções }\end{array}$ \\
\hline 01 & $\mathrm{~F}$ & 63 & $\begin{array}{l}\text { AVC+ } \\
\text { Diabete }\end{array}$ & Sacro+Calcân. & $13^{\circ} / 16^{\circ}$ & $\mathrm{IV} / \mathrm{II}$ & $\mathrm{S} / \mathrm{N}$ & $\mathrm{S} / \mathrm{N}$ & $1,6,0 / 1,6,4$ & $(+)$ & 36 \\
\hline 02 & $M$ & 56 & $\begin{array}{l}\text { Esofagoco- } \\
\text { loplastia }\end{array}$ & Sacro+Troc.D & $21^{\circ} / 17^{0}$ & III/ II & $S / S$ & $\mathrm{~S} / \mathrm{N}$ & $\mathrm{B}, 2, \mathrm{D} / 1, \mathrm{~A}$ & $38 / 26$ & 32 \\
\hline 03 & $M$ & 58 & $\begin{array}{l}\text { Fratura de } \\
\text { Quadril + } \\
\text { MIE }\end{array}$ & Sacro+Calcân.E & $9^{\circ} / 19^{\circ}$ & $\mathrm{III} / \mathrm{II}$ & - $S / S^{*}$ & $\mathrm{~N} / \mathrm{N}$ & $1,6,2 / 1,6,3$ & $43 / 24$ & 34 \\
\hline 04 & $\mathrm{~F}$ & 73 & $\begin{array}{l}\text { Vulvecto- } \\
\text { mia+Deis- } \\
\text { cência }\end{array}$ & $\begin{array}{l}\text { Sacro+Maléolo } \\
\text { Ext.E }\end{array}$ & $7^{\circ} / 15^{\circ}$ & $\mathrm{III} / \mathrm{II}$ & $S / S^{*}$ & $\mathrm{~S} / \mathrm{N}$ & $\begin{array}{c}1,6, \mathrm{D}, \mathrm{G} / \\
1,6,4\end{array}$ & $58 / 28$ & 47 \\
\hline 05 & $F$ & 70 & $\begin{array}{l}\text { Pneumec- } \\
\text { tomia } \\
\text { SEPSIS }\end{array}+$ & Calcâneo D. & $16^{\circ}$ & $\|$ & $S$ & N & $5,1, C$ & 38 & 26 \\
\hline 06 & $\mathrm{~F}$ & 68 & $\begin{array}{l}\text { Mastecto- } \\
\text { mia } \\
\text { Diabete }\end{array}+$ & Isquiática D. & $21^{\circ}$ & ॥ & $S$ & N & 5,1 & 36 & 22 \\
\hline 07 & $M$ & 48 & $\begin{array}{l}\text { Cistectomia } \\
\text { Total+Bexi } \\
\text { ga ileal }\end{array}$ & Sacro-Coccigea & $12^{\circ}$ & $\|$ & $\mathrm{S}^{*}$ & $\mathrm{~S}$ & $5,8,5,0$ & 56 & 42 \\
\hline 08 & $\mathrm{~F}$ & 59 & $\begin{array}{l}\text { Fratura } \\
\text { Colo de } \\
\text { Fêmur D }\end{array}$ & Sacro-Coccigea & $17^{\circ}$ & III & $S$ & $S$ & 2,6 & 37 & 18 \\
\hline 09 & $M$ & 38 & $\begin{array}{l}\text { Lesão de } \\
\text { Coluna C3 }\end{array}$ & TrocantE / Sacro & $27^{\circ} / 24^{\circ}$ & III / IV & $\mathrm{S} / \mathrm{S}^{*}$ & $\mathrm{~N} / \mathrm{N}$ & $\mathrm{H}, 6 / 1,7$ & +50 & 19 \\
\hline 10 & $\mathrm{~F}$ & 68 & $\begin{array}{l}\text { Pneumec- } \\
\text { tomia E }\end{array}$ & $\begin{array}{ll}\text { Maléolo } & \text { Ext. } \\
\text { D. +lsquio D. } & \end{array}$ & $21^{\circ} / 19^{\circ}$ & $\|/\|$ & $\mathrm{S} / \mathrm{S}^{*}$ & $\mathrm{~N} / \mathrm{N}$ & $7, A / 7, A$ & $26 / 39$ & 20 \\
\hline 11 & $\bar{F}$ & 64 & $\begin{array}{l}\text { AVC+ } \\
\text { Diabete }\end{array}$ & Sacro-Coccigea & $18^{\circ}$ & II & $S$ & $\mathrm{~S}$ & $1,6, \mathrm{D}, \mathrm{I}$ & 58 & 32 \\
\hline 12 & $\mathrm{~F}$ & 37 & $A I D S+B K$ & Sacro-Coccigea & $13^{\circ}$ & IV & $S$ & $S$ & $1,6, D, 4$ & $(+)$ & 20 \\
\hline 13 & $\mathrm{~F}$ & 48 & HAS+ AVC & Sacro-Coccígea & $24^{\circ}$ & \|I & $\mathrm{N}$ & $\mathrm{N}$ & $A, E$ & 27 & 21 \\
\hline 14 & $M$ & 33 & $\begin{array}{l}\text { AlDS+ } \\
\text { Pneumonia }\end{array}$ & $\begin{array}{ll}\text { Maléolo } & \text { Ext.E+ } \\
\text { Isquiát.E. } & \end{array}$ & $12^{0} / 17^{0}$ & II / III & $\mathrm{S} / \mathrm{S}^{*}$ & $\mathrm{~N} / \mathrm{S}$ & $0,1,6 / 3,1,7$ & $(+)$ & 42 \\
\hline 15 & $\mathrm{~F}$ & 66 & $\begin{array}{l}\text { CA Utebo+ } \\
\text { Metástase }\end{array}$ & Sacro-Coccigea & $27^{\circ}$ & III & $\mathrm{S}^{*}$ & $S$ & $F, 1, D, 3,6$ & +40 & 32 \\
\hline 16 & $M$ & 59 & Tétano & TrocantD./E & $14^{\circ} / 16^{\circ}$ & $\pi / \|$ & $\mathrm{N} / \mathrm{S}^{*}$ & $S / S$ & $\begin{array}{c}1,6, \mathrm{D}, \mathrm{E} / \\
1,6, \mathrm{D}, 1\end{array}$ & $46 / 57$ & 40 \\
\hline 17 & $M$ & 49 & $\begin{array}{l}\text { Meningite } \\
\text { Bacteriana }\end{array}$ & Calcâneo D & $9^{\circ}$ & $\pi$ & $S$ & $S$ & $1, \mathrm{E}$ & 27 & 15 \\
\hline 18 & $\mathrm{~F}$ & 72 & $\begin{array}{l}\text { Amputção } \\
\text { MID }\end{array}$ & Sacro + Calcân.E & $10^{\circ} / 16^{\circ}$ & III/ II & $\mathrm{S}^{*} / \mathrm{S}$ & $\mathrm{S} / \mathrm{N}$ & $1,6, F, E / 1, D, 3$ & $59 / 38$ & 26 \\
\hline 19 & $F$ & 66 & \begin{tabular}{l}
\multicolumn{2}{l}{ Gastrecto- } \\
mia Sub- \\
Tot.
\end{tabular} & Sacro-Coccígea & $17^{\circ}$ & $\|$ & $\mathrm{N}$ & $\mathrm{N}$ & $\mathrm{H}, 6, \mathrm{E}$ & 39 & 22 \\
\hline
\end{tabular}

Nota: De 01 a 07 (Hospital A), 08 a 13 (Hospital B), 14 a 19 (hospital C).

$(+)$ obtidos na fase de coleta de dados

+ .. pacientes que permaneceram com escaras após o período de coleta de dados 
No Quadro II observa-se que foram avaliados 554 tratamentos de escaras, sendo que $395(71,3 \%)$ estavam prescritos pelos médicos, especificando as medicações / produtos para a realização dos curativos, e em 159 (28,7\%) não estavam especificados. Ficando portanto, a cargo da equipe de enfermagem ou por conta de rotina a indicação dos mesmos.

Observa-se, no mesmo Quadro, que foram utilizadas 17 aplicações diferentes de combinações de substâncias no cuidado com as escaras. Destas 10 incluíam o uso da pomada Iruxol $®$. Nas 8 diferentes formulações prescritas pelos médicos, verifica-se que $4(50 \%)$ utilizam Iruxolß. Já nas 9 a cargo da equipe de enfermagem, nota-se o uso do Iruxol $®$ em 6 (66,6 \%). Portanto, verificou-se o uso de Iruxol® em $58,8 \%$ as terapêuticas vinculadas às úlceras de pressão.

O Quadro mostra ainda que as terapêuticas mais prescritas empregadas foram: LIMPEZA POLIVINILPIRROLIDONA IODO (PVP-I) + COM SORO FISIOLÓGICO 0,9\% + IRUXOL® com 133, isto é $24 \%$ do total de tratamentos analisados, seguida de LIMPEZA COM SORO FISIOLÓGICO (Cloreto de Sódio $0,9 \%)+$ IRUXOL $®$ e LIMPEZA COM ÁGUA DESTILADA + IRUXOL® (esta a cargo da Enfermagem), com 96 (17,3\%) e 49 (8,8\%), respectivamente.

\section{QUADRO DEMONSTRATIVO II - QUANTIDADE DE PRESCRIÇÕES MÉDICAS E TRA- TAMENTOS I CURATIVOS REALIZADOS PELA EQUIPE DE ENFERMAGEM, NOS PACIENTES PESQUISADOS COM ÚLCERAS DE DECÚBITO.}

\begin{tabular}{|c|c|c|}
\hline $\mathrm{N}^{\circ}$ de ORD & TIPOS DE TRATAMENTO DE ÚLCERAS DE DECÚBITO & Quantidades de Prescrições \\
\hline & A- PRESCRIÇÃO MÉDICA & \\
\hline 1 & Limpeza com SF 0,9\% + Polivinilpirrolidona iodo (PVP-I) + IRUXOL ${ }^{\circledR}$ & 133 \\
\hline 2 & Limpeza com SF 0,9\% + Sulfadiazina de Prata & 35 \\
\hline 3 & Limpeza com água oxigenada $\left(\mathrm{H}_{2} \mathrm{O}_{2}\right)+\mathrm{IRUXOL}{ }^{\circledR}$ & 29 \\
\hline 4 & Limpeza com SF 0,9\% + Fibrase ${ }^{\circledR}$ & 30 \\
\hline 5 & Limpeza com SF 0,9\% + Açúcar (granulado ou refinado) & 36 \\
\hline 6 & Limpeza com SF 0,9\% + IRUXOL ${ }^{\circledR}$ & 96 \\
\hline 7 & Limpeza com Clorodexina + IRUXOL ${ }^{\circledR}$ & 28 \\
\hline \multirow[t]{2}{*}{8} & Limpeza com SF 0,9\% + Triglicéridios de cadeia média (TCM) & 8 \\
\hline & B- CUIDADOS/TRATAMENTOS/CURATIVOS DAS ESCARAS & \\
\hline A & Limpeza com Ringer com Lactato (RL) IRUXOL ${ }^{\circledR}$ & 24 \\
\hline $\mathrm{B}$ & Limpeza com SF 0,9\% + Exposição aos raios solares + IRUXOL ${ }^{\circledR}$ & 10 \\
\hline $\mathrm{C}$ & Limpeza com SF 0,9\% + Carvão ativado & 12 \\
\hline $\mathrm{D}$ & Limpeza com SF 0,9\% + Desbridamento Mecânico + IRUXOL ${ }^{\circledR}$ & 11 \\
\hline $\mathrm{E}$ & Limpeza com água destilada + IRUXOL ${ }^{\circledR}$ & 49 \\
\hline $\mathrm{F}$ & Limpeza com $\mathrm{H}_{2} \mathrm{O}$ (chuveiro) + sabão de côco + SF 0,9\% + IRUXOL ${ }^{\circledR}$ & 17 \\
\hline G & Limpeza com SF 0,9\% + própolis & 16 \\
\hline $\mathrm{H}$ & Limpeza com SF 0,9\% + papaína & 12 \\
\hline 1 & Limpeza com SF 0,9\% + IRUXOL ${ }^{\circledR}+$ Hidrocolóide & 8 \\
\hline
\end{tabular}

OBSERVAÇÕES: A- Prescrições médicas das drogras/substâncias no tratamento

B- Prescrições médicas sem especificar as medicações, ficando a cargo da equipe de enfermagem. 
No Quadro III observa-se que a equipe responsável pelo tratamento e cuidados das úlceras de decúbito utiliza na sua rotina 24 produtos/substâncias, sendo que 10 são aplicadas em combinação com a pomada de Iruxol ${ }^{\circledR}$. Entretanto, por vezes, estas substâncias são empregadas pelos profissionais de saúde, sem observarem as condições mais favoráveis a ação para a qual o Iruxol ${ }^{\circledR}$ está indicado .

A presença de tecido necrosado e infeção levam a equipe a utilizar substâncias capazes de "esterilizar" e desbridar quimicamente a ferida. Em vista disso, observa-se o uso freqüente nos curativos de substâncias anti-sépticas combinadas com o Iruxol ${ }^{\circledR}$, que é terapêuticamente um limpador enzimático da lesão ${ }^{8,9,14}$.

Neste mesmo quadro encontramos os anti-sépticos prescritos e utilizados, indiscriminadamente, na rotina hospitalar, em associação com a colagenase (enzima componente do Iruxol ${ }^{\circledR}$ ), dentre eles destacam-se: a polivinilpirrolidonaiodo (PVP-I), a clorexedina, a água oxigenada e o sabão de côco, dentre outros.

\section{QUADRO DEMONSTRATIVO III - PRODUTOS EIOU SUBSTÂNCIAS USADAS NO TRATAMENTO DAS ÚLCERAS DE PRESSÃO ASSOCIADAS OU NÃO COM O IRUXOL ${ }^{\circledR}$}

\begin{tabular}{|c|c|c|c|}
\hline \multirow[t]{2}{*}{$\mathrm{N}^{\circ}$ de Ordem } & \multirow[t]{2}{*}{ TIPO DE PRODUTO / SUBSTÂNCIA } & \multicolumn{2}{|c|}{ ASSOCIADO AO IRUXOL ${ }^{\circledR}$} \\
\hline & & SIM & NÃO \\
\hline 01 & PVP-I (Aquoso, detergente ou alcóolico) & $x$ & - \\
\hline 02 & CLOREDEXINA (Aquosa, detergente ou alcóolica) & $x$ & - \\
\hline 03 & ÁGUA DESTILADA & $x$ & - \\
\hline 04 & ÁGUA OXIGENADA (10 volumes) & $x$ & - \\
\hline 05 & SORO FISIOLOGICO (NaCl) a 0,9\% & $x$ & - \\
\hline 06 & SABÃO DE CÔCO & $x$ & - \\
\hline 07 & RINGER COM LACTATO & $X$ & - \\
\hline 08 & ÁGUA POTÁVEL (chuveiro) & $x$ & - \\
\hline 09 & HIDROCOLÓIDES & $\bar{x}$ & - \\
\hline 10 & TINTURA DE BENJOIM & $\mathrm{X}^{*}$ & - \\
\hline 11 & ÓLEO MINERAL & - & $x$ \\
\hline 12 & VASELINA (líquida ou pastosa) & - & $\mathrm{X}$ \\
\hline 13 & PELICULUA DE CELULOSE & - & $x$ \\
\hline 14 & CARVÃO ATIVADO & - & $x$ \\
\hline 15 & FIBRASE ${ }^{\circledR}$ & - & $x$ \\
\hline 16 & IRUXOL ${ }^{\circledR}$ & $x$ & - \\
\hline 17 & TRIGLICERIIDIOS DE CADEIA MÉDIA & - & $x$ \\
\hline 18 & PAPAÍNA & - & $x$ \\
\hline 19 & PRÓPOLIS & - & $x$ \\
\hline 20 & SULFADIAZINA DE PRATA & - & $x$ \\
\hline 21 & AÇÚCAR (granulado ou refinado) & - & $x$ \\
\hline 22 & TROMBOFOB GEL ${ }^{\circledR}$ & $\mathrm{X}^{*}$ & - \\
\hline 23 & OXIDO DE ZINCO & $\mathrm{X}^{*}$ & - \\
\hline 24 & GELFOAN ${ }^{\circledR}$ & - & $x$ \\
\hline
\end{tabular}

NOTA: $X^{\star}=$ Substâncias usadas na pele periférica as lesões para prevenir irritações. 
O PVP-I e a clorexedina são encontrados nas Instituições de Saúde em três tipos de formulações: aquosa, detergente e alcóolica. Estas duas últimas não são indicadas para curativos de lesões abertas. Em contato com o tecido "vivo" causam irritações e ardência no local, devido a existência do detergente e do álcool em suas formulações, estes agridem e interferem no processo de recuperação das feridas. Além disso, a solução alcóolica e o detergente desnaturam a colagenase, inibindo a sua ação desbridante. O PVP-I aquoso é um dos produtos indicados para a anti-sepsia da ferida. Entretanto, só pode ser utilizado em associação com a colagenase quando se tiver a segurança que ela é tamponada e com o pH neutro, devido à possibilidade de reações no interior da lesão com a formação do ácido hiodídrico (HI). Em vista disso ocorrerá uma variação do pH da escara (teor ácido/base) para ácido, que provocará a desnaturação da colagenase e interferirá na sua ação desbridante.

Com o emprego de água oxigenada (peróxido de hidrogênio $-\mathrm{H}_{2} \mathrm{O}_{2}$ ) nas feridas infectadas, busca-se principalmente combater as bactérias anaeróbicas; possui também propriedades de limpeza das lesões. $A$ aplicação de $\mathrm{H}_{2} \mathrm{O}_{2}$ nas úlceras favoreça elevada liberação de oxigênio $\left(\mathrm{O}_{2}\right)$ o que favorece a alteração do $\mathrm{pH}$ nos exsudatos para ácido.

Quando se utiliza a água oxigenada $\left(\mathrm{H}_{2} \mathrm{O}_{2}\right)$ para limpeza de feridas como procedimento anterior a aplicação do Iruxol ${ }^{\circledR}$, observa-se uma redução de sua ação colagenolítica / desbridante.

A higiene do paciente com a prática do banho de chuveiro e a limpeza das escaras com sabões (sendo comum o uso do sabão de côco), não deve se constituir numa prática terapêutica adequada, uma vez que os sabões são fabricados à base de ácidos graxos de origem animal ou vegetal e soda cáustica. Esses elementos por si só geram uma reação adversa na lesão por se constituírem em corpos estranhos estimulando reações imunológicas defensivas. Por outro lado, a soda cáustica eleva acentuadamente o pH do sabão que em contato com a lesão provocará irritação pelo seu elevado teor alcalino.

Outro fator importante a ser analisado está vinculado à água; ela possui diversas substâncias que podem interferir no processo de cicatrização dependendo das concentrações de Flúor, Cloro e outros elementos veiculados na água. Quando a prescrição incluir o uso do Iruxol (R) deve-se atentar para a presença de substâncias halogenadas (Flúor, Cloro, lodo) porque elas desnaturam a colagenase reduzindo a ação proteolítica ${ }^{8,9}$.

As outras substâncias / produtos usados em associação com o Iruxol $₫$ nas Instituições pesquisadas foram: água destilada, cloreto de sódio a $0,9 \%$ (SF) e ringer com lactato.

O emprego da água destilada estéril é útil para limpeza das úlceras. Entretanto, por ser uma solução hipotônica em relação ao tecido lesado pode favorecer a absorção por osmose nas bordas da ferida levando a um "entumecimento" que prejudica a irrigação sangüinea dificultando, assim, o processo de cicatrização. 
A solução de cloreto de sódio a $0,9 \% \quad$ (SF) tem sido usada como principal produto para irrigação e limpeza de úlceras nas Instituições pesquisadas. Ela é uma substância com teor discretamente ácido.

A solução de ringer com lactato é utilizada para irrigação e limpeza das feridas infectadas, pelo seu teor alcalino uma vez um número importante de microrganismos ao agredir a lesão acidificam os exsudatos. Em vista disso, em feridas infectadas em que estiver prescrito o uso da pomada Iruxol $₫$, é recomendado o uso da solução de ringer para se obter melhores resultados ${ }^{8,14}$.

A outra associação com o Iruxol $\AA$, observada no estudo, foi com hidrocolóides. Os curativos oclusivos com hidrocolóides atuam como barreiras mecânicas a invasão bacteriana, além de manterem a lesão úmida, fator ideal para a migração das células essenciais para a cicatrização e que permitem a remoção do curativo sem traumas aos tecidos neoformados. Os hidrocolóides são constituídos de duas camadas: a interna, adesiva com partículas hidroativas aderida a um polímero inerte; e a externa composta de uma camada de poliuretano, flexível e impermeável à água e outros agentes externos. Por se tratar de uma experiência efetuada pela equipe de enfermagem em um paciente incluído na amostra deste estudo, não temos a clareza se o Iruxol $®$, neste caso estava sendo utilizado, de forma equivocada como cicatrizante ou pela ação do cloranfenicol (antibiótico de amplo espectro) que compõe a fórmula para manter a lesão livre de infeção. Em vista disso, há necessidade do aprofundamento de estudos neste assunto para ter-se as respostas mais efetivas sobre esta associação de produtos.

Como substâncias/produtos usados para proteger a pele circúnvizinha às úlceras de pressão foram encontrados: o óxido de zinco, a tintura de benjoim e o trombofob gel ${ }^{\otimes}$. Eles se mostraram bastante úteis no combate as agressões / irritações periféricas, pela sua ação protetora, combatendo os sinais flogísticos e o edema local. Com isso observa-se um estímulo à irrigação da epiderme e ao processo de cicatrização.

O Iruxol ${ }^{\circledR}$ na forma de pomada é indicado para uso tópico. Como recomendações sobre o modo de uso deve-se atentar para: 1- a pomada deve ter contato com toda a área lesada, com uma espessura de cerca de $2 \mathrm{~mm}$; 2- o efeito nas necroses crostosas é melhorado, fazendo-se cortes na sua superfície com bisturi, facilitando a penetração da enzima; 3- o material necrótico seco deve ser amolecido com compressas úmidas de ringer com lactato, soro fisiológico (cloreto de sódio $0,9 \%$ ) ou água destilada, facilitando a atividade desbridante da colagenase; 4- após a aplicação da pomada, cobrir a lesão com gaze úmida com uma das soluções citadas; 5 - o curativo deve ser mudado diariamente (a troca por duas vezes evidencia maior efeito enzimático); 6 - deve ser removido todo o material necrótico desprendido, em cada troca de curativo, com pinças, espátu- 
las ou através de lavagens; 7- lavar com as soluções já citadas, não usar detergentes, sabões ou soluções a base de metais pesados (mercúrio, prata, manganês, etc.) ou halógenos (flúor, cloro, iodo, etc.); 8- proteger as margens da lesão com pomadas de zinco ou similares; 9- no tratamento de feridas além da utilização do Iruxol $($, deve-se empregar paralelamente outras medidas e procedimentos terapêuticos adequados para favorecer a sua recuperação; 10- reações de hipersensibilidade aos componentes da fórmula; 11- há possibilidade de reinfecção, deve-se observar rigorosa higiene pessoal durante a utilização da pomada; 12- o uso prolongado de antibióticos pode, no caso do cloranfenicol, ocasionar ou provocar o desenvolvimento de microorganismos resistentes; 13- o emprego adicional de outros de aplicação tópica podem diminuir a eficácia terapêutica da colagenase; 14- ocorrência de ardência, dor, irritação, rubor e reações de hipersensibilidade ao antibiótico; 15- discrasias sangüineas, incluindo anemia aplástica, podem ocorrer com o uso do cloranfenicol tópico, sendo muito raras ${ }^{8,9,14}$.

\section{CONCLUSÃO}

A preocupação da equipe terapêutica (médica e de enfermagem) com as úlceras de pressão que apresentam, concomitantemente, tecido necrótico e infeção, tem levado esses profissionais ao emprego indiscriminado de diversas formulações terapêuticas.

Uma série de substâncias / produtos que são utilizados rotineiramente na limpeza e "esterilização" das feridas alteram de forma incontrolada o pH (teor de acidez / alcalinidade) do exsudato das lesões. Portanto, a colagenase utilizada sob a formulação do $\mid$ Iruxol ${ }^{\circledR}$, poderá sofrer um processo de desnaturação com prejuízos na sua ação colagenolítica (desbridante), quando o $\mathrm{pH}$ estiver abaixo de 6,5 (ácido) ou acima de 8,0 (alcalino).

A equipe não tem observado as alterações do $\mathrm{pH}$ nas feridas nem a sua influência no processo de reconstituição tissular, o que se constitui em um problema que necessita ser melhor trabalhado pelas equipes médica e de enfermagem.

A associação/combinação do Iruxol ${ }^{\circledR}$ com pensos ou substâncias que interferem nos niveis de $\mathrm{pH}$ das feridas, pode: aumentar o periodo de tratamento das escaras pela necessidade de tempo mais dilatado para desbridamento do tecido necrótico; proporcionar a resistência dos microorganismos ao cloranfenicol da fórmula; estimular a cronicidade das úlceras e ainda pode prejudicar a imagem do produto Iruxol ${ }^{\circledR}$ na terapêutica das úlceras e crostas. 


\section{REFERÊNCIAS BIBLIOGRÁFICAS}

1. BARDSLEY, C., FOWLER, H., MOODY, E., TEIGEN, E., SOMMER, J. Pressure sores: A regimen for preventingand treating them. Am. J. Nursing, n.1, p. 64-82, 1964.

2. BERECEK, K. H. Etiology of decubitus ulcers. Nurs. Clin. N. Amer., v. 10, n. 1, p. 157-59, 1975.

3. BOGHOSSIAN, L. C. Úlceras de pressão: Aspectos gerais e tratamento. Tese (Mestrado em Medicina) - Faculdade de Medicina, UFRJ. 1983.

4. BRUNNER, L. S., SUDDARTH, D. S. Tratado de enfermagem médicocirúrgica. 7. ed. Rio de Janeiro: Guanabara Koogan, 1993.

5. CAMPBELL, R. M., DELGADO, J. P. The pressure sore. In: Reconstructive plastic surgery. 2nd. Philadelpia, w. b. sauders company, v. 7, p. 37633799 .

6. CAMPBELL, J. W., FRISSE, M. Manual de Terapêutica Clínica. Tradução de Jayme Neves. 24ed. Rio de Janeiro: Medsi - Editora Médica, 1985.

7. DECLAIR. V. Efeito dos triglicéris de cadeia média (TCM) na aceleração do processo de cicatrização. Suprimentos \& Serviços Hospitalares, v. 1, n.1, p. 6-7, mar./abr. 1995.

8. DEF. Dicionário de Especialidades Farmacêuticas. Rio de Janeiro: JBM, Wellcome. Publicações Científicas, 1995/1996.

9. KNOLL. - Bula da pomada Iruxol. Rio de Janeiro: 1996.

10. LOWTIAN, P. Pressure sores prevalence - A survery of sores in orthopedic patients. Nursing Times, v. 75, n. 11, p. 358-60, 1979.

1T. MARINHO, A. M. Úlceras de pressão em pacientes com problemas tráumato-ortopédicos: implicações para a enfermagem relacionadas com os recursos de prevenção. Tese de Mestrado, Rio de Janeiro, UFRJ, EEAN, 1985.

12. MARTINS, T. et al. Tratamento de feridas. Nursing , v. 9 , n. 100, p. 30-38, maio, 1996.

13. McCORMIC, W. J. The nutricional aspects de bedsores. Medical Record, n.154, p. 389-391, 1991.

14. MERCK. The Merck index. 12. ed. 1996. 
15. MULHOLLAND, J. H. , et al. Protein metabolism and bedsores. Am. surg. $\mathrm{n}$. 118, p. 1015-1023, 1983.

16. PFAUDLER , M . -Flotation displacement and decubitus ulcers. Am . J . Nursing, v. 68, p. 2351-2355, nov. 1968.

17. RUBIN , C. F. , DIETZ, R. R . EABRUZZESE, R. S . - Auditing the decubitus urcer problem. Am .J. Nursing, v. 74, n. 10, p. $1820-1,1974$.

18. SNOWDEN, D. A basic guide to nursing care. Nursing Mirror, v. 1, p.2225, feb. 1979.

19. TIAGO, F. Feridas etiologia e tratamento. 2.ed. Ribeirão Preto: S. P. FAEPA, 1995.

20. WOODBINE, Anne - Pressure sores 1: A review of the problem. Nursing times, p. 1087-88, jun. 1979. 